\title{
Human Resource Management Practices and Employee Turnover Intentions Nexus: Does the Mediating Role of Job Satisfaction Matter?
}

\author{
Isaac Kofi Dasilveira1, Jingzhao Yang1*, Isaac Adjei Mensah², Alfred Quarcoo² \\ ${ }^{1}$ Department of Business Administration, School of Management, Jiangsu University, Zhenjiang, China \\ ${ }^{2}$ Insttitute of Applied Systems and Analysis (IASA), Jiangsu University, Zhenjiang, China \\ Email: ^237599701@qq.com, *isaacadjeimensah29@outlook.com
}

How to cite this paper: Dasilveira, I.K., Yang, J.Z., Mensah, I.A. and Quarcoo, A. (2020) Human Resource Management Practices and Employee Turnover Intentions Nexus: Does the Mediating Role of Job Satisfaction Matter? Open Journal of Business and Management, 8, 1-29. https://doi.org/10.4236/ojbm.2020.81001

Received: October 13, 2019

Accepted: November 22, 2019

Published: November 25, 2019

Copyright $\odot 2020$ by author(s) and Scientific Research Publishing Inc. This work is licensed under the Creative Commons Attribution International License (CC BY 4.0).

http://creativecommons.org/licenses/by/4.0/

\begin{abstract}
This current paper explores the nexus amid human resource management practices and employee turnover intentions in private organizations in an evolving economy, Ghana. Particularly, the study is centered on the mediating role of job satisfaction within the relationship between human resource management and employee turnover intentions. The study depended solely on a survey approach through purposive and simple random sampling techniques. The survey was conducted among the top ten private organizations in Ghana via purposive sampling approach whereas the simple random sampling method was used to select 20 respondents from each selected firm. A total of 200 questionnaires were administered, of 186 were valid to be used representing a response rate of $93 \%$. The application of a path analysis approach showed that; 1 ) both HRM practices and job satisfaction have a significant negative effect on employee turnover intentions, 2) there is a significant positive relationship between HRM practices and job satisfaction, 3) job satisfaction efficiently mediates the relationship between HRM practices and employee turnover intentions. The results from the analysis statistically indicate that leaders in various private organizations must develop a strategy by which they can improve management practices to enhance employee job satisfaction, which will then reduce or have a negative effect on employee turnover intensions. We thus conclude that job satisfaction really matters within the affiliation between HRM practices and employee turn intentions.
\end{abstract}

\section{Keywords}

Human Resource Management, Employee Turnover Intentions, Job Satisfaction, Path Analysis, Ghana 


\section{Introduction}

Turnover intention is defined as individual movement across the membership boundary of an organization [1]. Interestingly unlike actual turnover, turnover intent is not explicit. Intentions are a statement about specific behavior of interest. Studies have shown that turnover is one of the most researched phenomena in organizational behavior [2]. The broad range of turnover studies is indicative of the significance and complexity of the issue. The phenomena attract interest due to its psychological dimension, its organizational significance and its economic dimension. Thus, it is imperative for HRM managers to understand that there are several factors inherent to counter staff intentions or turnover. One theory specifies employee's decision to resign is influenced by two factors which include their perceived ease of movement which is referred to as the assessment of perceived alternatives and perceived desirability of movement which is influenced for instance by job satisfaction [3]. This describes how balance is struck both for the organization and its employees in terms of inducements such as par and contributions, work which ensures continued organizational efficiency. In general, when inducements are increased by the company, this will lower the tendency of the worker to leave and vice versa. At the same time managers should be aware of the question whether the decision to leave could have been prevented by the organization. This is important for the planning of interventions. It would be realistic to manage this turnover as unavoidable rather than spend on theorized preventive measures such as increasing pay.

Measuring employee turnover is helpful to employers that want to examine reasons for turnover or estimate the cost-to-hire for budget purposes. Research in the area of turnover is still extremely relevant as the phenomenon is relatively complex to understand. Employee behavioral models and many other forms of research have been carried out and still a lot more is yet to be understood [4]. Human resource management (HRM) infers that workers are assets of the business. The impact of Human Resource Management can have a profound negative effect on the organization. The expectancy theory predicts that one level of motivation depends on the attractiveness of the rewards sought and the probability of obtaining these rewards can hold sway in any current organization managements' objective to achieve high productivity and competitive edge in the market place. Employees therefore desire compensation system that perceives as being fair and commensurate with skills and expectations. Pay therefore is a major consideration in an organization as well as source of recognition and livelihood ([1], [3]). [5] characterized HRM practices as a strategic and vital approach to accomplish, secure, oversee and spur as well as picking up the steadfastness of the workers. HRM practices are analyzed as the accessible talent and energies of individuals who are accessible to an organization as conceivable supporters of the creation and fulfillment of the organization's mission, vision, strategy and objectives [6].

Having established the importance of human resource management practices 
on employee retention, it is important to state that different approaches to human relations have different results. The relationship between the employer and the employee determines the strength of effects on trust, loyalty, satisfaction and turnover intention [4]. Employees who feel a part of the firm and whose inputs and contributions are considered in the running and decision-making process are less likely to quit their jobs and so get engaged over long periods than those who feel sidelined by management. Employees whose managers relate with them in poor ways, hinders optimum state and performance; resulting in poor job satisfaction, low personal fulfilment, poor sense of belongingness and others. This lack of trust between manager and employee has one possible outcome as lack of job satisfaction, hence catalyzing the intention of employee to quit for better alternatives. The role of trust and job satisfaction can therefore not be taken for granted by firms in aspiring for the best output for sustainable business. Many researchers have carried out studies in the area of employee turnover intentions and the effect of human resource management practices with little attention on role played by job satisfaction. Job satisfaction is a factor that would induce the employee to work in the long term position. Regardless of job satisfaction the organization or firm would be confronted with cost of recruitment which caused by turnover due to poor management practices. For this reason much attention must be paid to job satisfaction when investigating the relationship between human resource management practices and employee turnover intentions. This study intends to fill the knowledge gap in understanding the effects of human resource practices on employee turnover intentions through the mediating role of job satisfaction using Ghanaian private organizations as the study case. In summary the concept of this study is illustrated in Figure 1.

The remainder of the paper is as follows; Section 2 briefly reviews relevant literature, Section 3 discusses the methods as well as data source of the study, Section 4 reports the empirical results whilst Section 5 gives summary of findings and conclusion to the study.

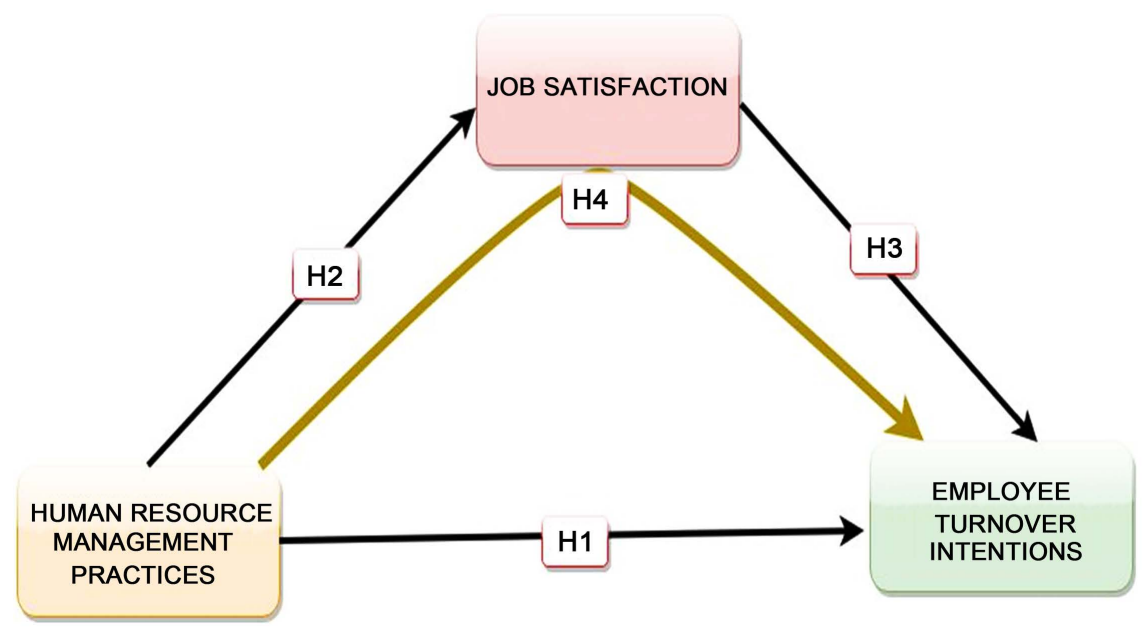

Figure 1. Conceptual model. 


\section{Literature Review and Hypothesis Development}

This section of the study briefly reviews past and recent literature corresponding to human resource management practices, job satisfaction and employee turn-over intentions as well as their linkages. The discussed related works provides the fundamentals from which hypothesis are developed.

Job satisfaction is in regard to one's feelings with respect to nature of their work. Job satisfaction can be influenced by variety of factors which may include pay practice, quality of one's relationship with the supervisor, quality of physical environment in which they work whereas turnover on the other hand refers to the characteristics of a given company, relative to the rate at which an employer gains or losses staff. For instance if an employer is said it has a high turnover, then it implies that employees of that firm have a shorter tenure than those of other companies in that same industry. Job satisfaction and turnover are basically related by which job satisfaction has a direct effect on employee turnover intentions. Furthermore, in line with the studies conducted by [7] job satisfaction is generally associated with increment in productivity, absenteeism and lower employee turnover. Assertion by [8] stressed that Job satisfaction is found to have a direct negative relationship with turnover intentions. These outcomes indicate that the effect of job satisfaction on turnover intentions can be enhanced when employees find congruence between their job and their self-identity and also when involvement in such jobs enhances overall life satisfaction. On the other hand, turnover intentions of employees can be regarded as cost of running a business. According to [9], the effects of turnover in terms of labor on hotel's bottom line could be classified into direct costs and indirect costs where the direct costs include the administrative cost as a result of increased number of employees and training expenditure for newly employed staff. Employee turnover not only takes away the talents of the organization but also hampers the smooth operation of the organization ad increases coasts as well. Thus, the aftereffect of such departure is well acknowledged in creating interruptions to the usual process of an organization and lessening the performance as well [10]. Research in a variety of disciplines has long suggested that minimizing turnover intentions has a high potential to minimize actual turnover, since it is considered as the precursor of actual turnover [11]. Drawing on a variety of theoretical perspectives, it is suggested that Human Resource Management (HRM) practices have an immense impact on turnover intention in different contexts [12]. HRM practices according to [13] have shown intense importance within the HRM field in terms of how HRM can aid employee attachment with the organization through increasing their level of commitment and thus leading to a growing focus on new dimension of HRM. The relationship between HRM practices and job satisfaction is ambiguous with respect to wage theories. However, there are some distinct studies such as [14] who examined the overall job satisfaction of Dutch public workers considering their pay as an HRM practice. The results revealed that there is positive influence of 
HRM practice which in this case is pay practice on the job satisfaction. Likewise, [15] observed the impact of HRM practices on worker's job satisfaction. On their study they employed HRM practices such as work organization, recruitment and pay practice as independent variables and job satisfaction as dependent variable. Results from their study thus showed a positive relationship between HRM practices (pay practices) and job satisfaction. Relying on the above assertions that have been introduced briefly with respect to the variables understudy various hypothesis are developed in the subsequent sections as follows:

\subsection{Liaison between HRM Practices and Employee Turnover Intention}

Human resource management affects the attitude and behavior of employees. Specifically, employee turnover intention is one of the behaviors that human resource management can influence [16]. Human resource management can be associated with the exit decision process. Human resource management may not only have a positive impact on employees, but also have a negative impact on employees, leading to employees' dissatisfaction. An example is when employees are not satisfied with training and development opportunities and do not receive the regular feedback they expect. In addition, employees may experience high levels of stress due to increased work intensity. In this way, they are experiencing that their work-life balance is unbalanced. These feelings of dissatisfaction will lead to thoughts about resignation and increase the intention to leave [17].

This shows that it is very necessary to design a human resource system that can have a positive impact on employees' attitudes and behaviors, so as to reduce employees' turnover intention. The relationship between HRM and turnover intention can be explained by different theories, including capability, motivation and opportunity (AMO) theory and social exchange theory. Starting with AMO theory, feedback from HPWPs is helpful for learning and self-efficacy. This will increase employees' confidence in their ability to do the job. Enhanced staff's attitude towards the importance of work through the PWP's autonomy in work decisions. If employees think their task is important, they will be more motivated to do it. The opportunity for employees to participate in job design so that employees feel their voices are important in the organization and they can make a difference in their work. Organizations that provide these resources and support are more motivated to make a meaningful contribution to employment. The AMO model supports the relationship between human resource management and turnover intention, because human resource management can enhance the three main components of the AMO model (capability, motivation, and opportunity). This ensures that employees have a strong sense of belonging to the organization and are motivated to stay. In addition, meta-analysis of organizational behavior studies shows that employees who perceive high relative salary, employment security, salary satisfaction, career development opportunities and other human resource incentives have low turnover rate [18]. Employees who have more autonomy and control over their work and family rela- 
tionships are less likely to quit their current jobs. Therefore, jobs designed to increase decision-making autonomy will reduce turnover intentions.

In addition to AMO theory, the relationship between HRM and turnover intention can be explained by social exchange theory. An efficient human resource system relies on establishing a relationship between managers and employees based on mutual investment. In this relationship, managers invest in the skills and opportunities of their employees. Managers, in turn, want employees to be qualified and motivated to make valuable job-related investments in the organization. Therefore, the relationship between employees and managers can be regarded as a social exchange. Social interaction refers to the cooperation between two or more parties for mutual benefit. According to the study of [19], social interaction includes some ambiguous obligations, in which individuals help others and expect some return in the future. The form and timing of returns are often unclear. Social exchange may also involve reciprocity, defined as the obligation of the beneficiary to repay the donor in some way. Strong emotional bonds to the organization may be the result of positive mutual social exchange between managers and subordinates. In this study, the interest was in behaviors that reflected this association. Intention to stay in the organization represents the behavioral outcome of employees' emotional ties to the organization. This can be reflected in the desire to see the organization succeed in its goals and the pride of being a part of the organization [20].

Effective human resource practices, if implemented effectively, are likely to make employees perceive their communication relationship with their manager as characterized by a supportive environment. This is based on investment in employee skills, regular and fair performance feedback, fair and attractive rewards for performance, and joint efforts to achieve meaningful goals [21]. In return, employees may feel obligated to meet the goals of their managers and organizations. Therefore, they establish an emotional relationship with the manager and the organization itself, which is based on a mandatory reciprocal relationship in their exchange relationship [22]. Employees who are more involved in the organization may display this emotional bond more naturally. In particular, these employees are likely to act in the best interests of their organization. In addition, employees who are actively involved in the management of high-performing human resource systems may feel the desire and obligation to contribute to organizational [20]. They may be more likely to stay with the company than less involved employees. There are several reasons for this. First, employees want to contribute to the effectiveness of the organization only when they continue their employment relationship. In other words, employees' desire to help achieve organizational goals is consistent with their intention to stay in the organization. Second, employees will leave the company if they think their rewards no longer match their contributions. Wanting to leave represents a form of retreat. This may be due to a lack of emotional attachment to the organization and its goals. The core hypothesis of social exchange theory is that human resource management practice is regarded as the individual commitment of an 
organization to employees from the perspective of employees. Employees repay the company by their willingness to remain with the company [23]. In summary, HPWPs are a synergy of performance and commitment to enhance human resource practices, each of which contributes to higher organizational and employee performance [18]. Turnover intention can be explained by the turnover decision-making process. Turnover intention refers to the intention of an employee to leave the current organization. The relationship between HRM and turnover intention can be explained by AMO theory and social exchange theory. HPWP for employee empowerment, employee motivation, and employee engagement opportunities (AMO) seems to create a strong bond between employees and the organization. This, in turn, will have a negative impact on employees' turnover intention. In other words, human resource management is negatively correlated with employee turnover intention, because employees are less likely to leave the organization and have an effective human resource system. According to the social exchange theory, strong emotional ties to the organization may be the result of a positive mutual exchange relationship, which will lead to lower turnover intention and stay in the organization. We therefore test the hypothesis that;

Hypothesis 1: Human resource management (HRM) negatively influences employee turnover intentions.

\subsection{Liaison between HRM Practices and Job Satisfaction}

Developing a positive attitude toward the employee's job is expressed as satisfaction. As a result, employees want to fulfil their work expectations in an appropriate environment and under appropriate circumstances in return for their work performance. By so doing, the more their expectations are fulfilled the higher the job satisfaction, [24]. [25] in their study, employed explanatory research, using questionnaire to collect data from a sample of 100 respondents. Data were analyzed by using correlation and regression statistical tools. And concluded that, there was a significant relationship between training and development and job satisfaction. [26] employed exploratory and descriptive research design. A sample of 125 respondents was randomly selected. Questionnaires were used to collect data. Results concluded that training and development contribute positively, to job satisfaction. [27] studied job satisfaction and training and development using a sample of 237 respondents and self-administered questionnaire. Data were analyzed by using descriptive statistics and paired test tools. Results revealed once again that, training and development as HRM practice has a positive effect on job satisfaction in an organization. Similarly, [28] studied the effect of HRM practice (training of workers) on job satisfaction by using 250 employees. Data were collected by using questionnaires and analyzed by correlation and regression analysis. The results suggested that, there was strong positive relationship between training of workers as HRM practice and employees job satisfaction. [29] maintained that, employees who have chance to get training and development opportunity are more satisfied with their job in organization. [30] 
in their study on the impact of compensation on job satisfaction, using sample of 265 respondents selected by stratified randomly sampling techniques. Data were analyzed by using confirmatory factor analysis tool. The study revealed that HRM practice (compensations) have positive impact on employees' job satisfaction. [31] studied the effect of compensation factors on employee's satisfaction. Simple random sampling technique was used in this research and correlation, ANOVA and regression analysis tools were applied. Results showed that pay, recognition, promotion and meaningful work had effect on job satisfaction. [32] studied effects of compensation package on job satisfaction. They used a cross sectional study and self-reported questionnaire survey on a sample of 457 respondents from USA, 391 respondents from Vietnam, and 347 from Malaysia. Data were analyzed with ANOVA, descriptive statistics and regression analysis. Findings revealed that compensation packages used as HRM practices, namely; pay, recognition and benefits have positive effect on job satisfaction. [33] studied the influence of employees' compensation on job satisfaction in using 270 questionnaires and correlation and regression analysis techniques. The results indicated that, there was positive significant relationship between compensation and job satisfaction.

[34] studied the HRM practices and job satisfaction by using cross sectional survey strategy, questionnaires, regression analysis and samples size were 10,500 of employees. Findings from the study show that, there is a positive significant effect of performance appraisal and job satisfaction. [35] adopted the survey research strategies and total of 570 questionnaires were used for analysis, correlation analysis and multiple regression analysis were used in data analysis. The results revealed that HRM practices had strong significant positive impact on job satisfaction. [36] surveyed 120 respondents through questionnaire administration; data were analyzed by using Pearson correlation analysis and concluded that, HRM practices have a significant relationship with job satisfaction. In addition, [37] adopted a case study research design to study, the effect of HRM practices on job satisfaction and used interviews to collect data and descriptive statistical analysis to analysis data. Results showed that, that there is a positive relationship between HRM practices and job satisfaction. Since HRM practices is a significant determinant of job satisfaction of employees, the notion helps to develop the following hypothesis:

Hypothesis 2: Human resource management (HRM) positively affects job satisfaction.

\subsection{Job Satisfaction and Employee Turnover Intentions}

Resignation intention is one of the important manifestations of employee dissatisfaction [38]. Researchers have developed conceptual frameworks to model the flow of people. As [39] pointed out, scholars speculate that employee turnover rate can be predicted by comprehensive indicators of job satisfaction. In other words, high job satisfaction is associated with low employee turnover. In addition, studies show that the relationship between job satisfaction and actual em- 
ployee turnover rate is regulated by intention. [40] pointed out that in dozens of studies exploring turnover intention and actual turnover behavior, positive and statistically significant relationships have been reported. In other words, the intention of resignation is a direct precursor to actual resignation. Therefore, in the published literature, turnover intention is included in most employee turnover models. Resignation intention refers to an employee's desire to find a new job in another company within the next year. [41] found a strong negative correlation between job satisfaction and resignation, and believed that understanding of overall job satisfaction was the main predictor of analyzing employee turnover intention. Studies on job satisfaction and turnover intention found that in different employee groups in different countries, such as private institutions in Taiwan [38]. [42] confirmed the negative correlation between teachers' job satisfaction and resignation intention. In recent years, the employee turnover rate is on the rise [43]. According to the research of [44], when employees' dissatisfaction with their work exceeds their satisfaction with their work, they will leave the organization. When many employees are dissatisfied with their work experience, it will lead to high turnover rate and unnecessary cost of the organization [45]. For organizations, it is important to reduce turnover rate because employees who leave the organization tend to perform better than average [44].

In order to consider the hypothetical relationship between job satisfaction and turnover, we will explain the social exchange theory (SET) [46]. This set is a theory that makes behavior in the workplace understandable [47]. Social exchange involves a series of interactions between individuals, which are usually regarded as interdependent and dependent on the behavior of another person. This set of data shows that the reciprocity expected by individuals can justify their expenditure in terms of time and energy. Reciprocity norms are associated with these sets, which refer to behaviors that rely on others' return reactions and stop when these expected reactions do not occur [46]. So when someone does something for someone, that person feels obligated to do something in return, and conversely, when someone doesn't do anything for someone, that person does not feels obligated to do something in return. From the perspective of an employee, he/she is not satisfied when he/she feels that the organization does not give him/her enough time and energy [47]. This results in employees doing less for the organization. This means that employees will leave the organization and look for another organization with a good social exchange relationship. In addition, the resignation theory of [48] also explains the hypothetical relationship between job satisfaction and resignation intention. The theory holds that job satisfaction varies with the assessment of current working conditions and characteristics. He points out that job satisfaction varies with the impact of an employee's work experience, which means that when employees are less satisfied, they are more willing to leave the company. The unfolding model of turnover [49] is consistent with [48] theory of turnover intention, which makes the hypothetical relationship stronger. Both theories suggest that employees are more likely to leave the organization due to their assessment of current working con- 
ditions and characteristics, so their satisfaction may be reduced. This means that there is a negative correlation between job satisfaction and turnover intention.

Empirical evidence of the relationship between job satisfaction and turnover intention has been evidenced. [40] believes that the higher the job satisfaction is, the lower the turnover intention is. [50] and [51] agree on this relationship. [52] also found a negative correlation between job satisfaction and resignation intention. Therefore, based on such a set, when an employee feels that the organization does not give him/her enough effort and time, the employee will do less for the organization. Therefore, employees will find another organization with good social exchange relations. Secondly, the turnover theory and turnover expansion model show that job satisfaction will decline with the assessment of current working conditions and characteristics, leading to higher turnover intention. Based on the SET, the theory of turnover, the empirical evidence and own reasoning, the following hypothesis has been formulated:

Hypothesis 3: The higher the level of job satisfaction, the lesser the level of employee turnover intention. In other words, job satisfaction has a negative influence on employee turnover intentions.

\subsection{Job Satisfaction as a Mediator}

Researchers found that job satisfaction plays an intermediary role between internal service quality and organizational performance; time stress and health outcomes and core self-evaluation and burnout [53]. In the analysis of turnover intention, researchers also found the role of job satisfaction as an intermediary ([33]; [54]). Job satisfaction mediates the influence of salary and promotion on turnover intention [55]. [56] found that job satisfaction plays a partial intermediary role in the influence of competitive salary, career promotion opportunities, challenging working environment and learning culture on the talent flow intention of Indian business process outsourcing organizations. Therefore, these study findings help to constitute the following hypothesis:

Hypothesis 4: Job satisfaction intervenes between Human resource management (HRM) and employee turnover intentions.

The aforementioned hypotheses can be translated into a conceptual model, which is presented in Figure 1 as.

The research conceptual model from Figure 1 was developed relying on relevant literature. The conceptual model shoes the analysis model with all variables. Further, it depicts the affiliations between human resource management practices, job satisfaction and employee turnover intentions. Depending on other related works as discussed already in the literature section, four (4) different hypotheses were developed to investigate the effect of human resource practices on employee turnover intentions with job satisfaction playing a mediating role. Summarily the four developed hypotheses introduced to demonstrate the mediating function of jib satisfaction are as follows;

$\mathrm{H1}$ : Human resource management (HRM) negatively influences employee turnover intentions. 
H2: Human resource management (HRM) positively affects job satisfaction.

H3: The higher the level of job satisfaction, the lesser the level of employee turnover intention. In other words, job satisfaction has a negative influence on employee turnover intentions.

H4: Job satisfaction intervenes between Human resource management (HRM) and employee turnover intentions.

\section{Methodology}

This current study seeks to examine the causal affiliations between the factors such as HRM practices, job satisfaction and employee turnover intentions. The study empirically is an applied research which entirely depends on survey data from private sector organizations in Ghana. Due to the size of the population of private enterprises in the country, it will be very difficult to conduct such a survey without sampling. This is justified by Punch (2013) who posited that, one cannot study everyone, everywhere, doing everything thus sampling decisions are deemed necessary. Base on this view, the study purposely selected the top ten (10) private enterprises in Ghana which includes Newmont Golden Ridge Limited, Ghana oil company, Goldfields Ghana Limited, MTN group, Vivo Energy Ghana, Unibank Ghana limited, Mutlipro Limited Ghana, Nordea Capital limited, Justmoh Construction Limited and Total Petroleum Ghana [57]. These private entities were chosen with the reason being that, they contribute significantly to humanity as well as the economy of Ghana. Also the participation private firms employ at least 100 full time employees. The selection criterion therefore eliminates small and/or very small private firms and thus enables the study to obtain robust results to draw enormous policy implications. Due to the survey nature of the study, a well-structured questionnaire was employed as a main instrument of data collection. The structured questionnaire was developed with the help of a collection of prior designs used in related studies. Questionnaire for the study was designed mostly using closed ended method together with the Likert-scale method. The close-ended questionnaire helped in predetermining the standard responses that were deemed appropriate for the study and also helped to guide and made it relatively easy for the respondents in choosing particular answers. It must however be stated that questions that demanded some probable answers such as agree and disagree, the study employed a Likert scale of five points (5 - 1) in designing the appropriate questions to facilitate in soliciting for the necessary data suitable for the study (i.e. $5=$ highly agree whiles $1=$ highly disagree). The questionnaire was carefully designed to cover and evaluate all the variables of the study. Since a subject's ratings cannot be divorced from its perceiver, this study sampled most knowledgeable respondents from each firm who are experts to give accurate responses on each construct within the questionnaire. Specifically, the essential source of information were obtained from employees of the selected private firms key informants. This selection according to [58] provides highly relevant perspectives in the context of innovations. Respondents for the study were contacted via personal interview 
and online survey. Perceptions of respondents about their knowledge on various constructs use in the study were questioned so as to ensure they were suitable and confident to give accurate responses. After the questionnaire design, researchers deemed it necessary to check whether the instrument is reliable and can lead to the collection of valid information to draw valid conclusions. In other words, reliability in this sense is the ability of the data collection instrument to collect the same data when administered at different places and at different times. To this end a questionnaire was pretested using ten pretest samples that were selected from the population but not part of the sample. The questionnaire was administered using the split-half method in order to determine the internal consistency at different places at different times. Based on the compilation and analysis with respect to the final responses, it was necessary to make changes to the questions in terms of the wording and as well convert some open ended questions into closed ended due to the fact that respondents had different taught which might lead to inconsistent findings. A second pretest was further conducted on ten respondents making up five from the previous pretest sample and five addition samples selected from the respondents. The results showed a much more improves instrument after the second pretest and for that matter commenced the data collection.

In this study, a total of 200 questionnaires were distributed to target respondents to collect data on human resource management practices, job satisfaction and employee turnover intention in private enterprises in Ghana. The results of questionnaire response rate are shown in Table 1. There's obviously a higher response rate. High response rate is advantageous, because compared with low response rate, high response rate greatly reduces the non-response rate bias. Low response rates pose a risk to a study because non-responders are likely to differ greatly from responders in other ways than their willingness to participate in the study.

Table 1 reveals that 186 out of 200 sampled respondents from the selected private organizations responded to the questionnaires completely. This commendable response rate from the participants can be attributed to the technique used by the researcher in collecting the data. The researcher only considered the dully filled questionnaires for analysis which accounted for $93.0 \%$ response rate thus ideal for the study analysis to progress.

\subsection{Measurement of Constructs}

In the context of construct measurement, the questionnaire was structured to

Table 1. Rate of responses from respondents.

\begin{tabular}{ccc}
\hline Response & Frequency & Percentage \\
\hline Responded & 186 & 93.0 \\
Not responded & 14 & 7.0 \\
Total & 200 & 100.0 \\
\hline
\end{tabular}


evaluate the relationship between three (3) main constructs which includes HRM practices an independent variable, job satisfaction as a mediating variable and employee turnover intention as the response variable. In details, HRM practices as the only independent variable was measured using thirteen (13) items developed by [16]. The measurement items for the aforementioned construct were all assessed on a five-point Likert scale ranging from strongly disagree to strongly agree. The study further measured the mediating construct (job satisfaction) with a total number of seventeen (17) items scale. All the items used in measuring this construct were adopted from [57] with a five (5) point Likert scale ranging from strongly disagree (1) to strongly agree (5) Finally, the employee turnover intentions which is employed as the main response variable in our study was on the other hand measured relative to only eight (8) items from the 15 item scale of [58] on a five-point scale with the scale poles also ranging from strongly disagree (1) to strongly agree (5). Details of the constructs and their respective measurement items or statements are presented in Table A1 from the Appendix. In addition to the independent, mediating as well as dependent variables respectively, the demographic characteristics of respondents which includes; age, gender, education level, and marital status were also measured. Age of respondents were measured based on five categories (20 - 25, 26 $30,31-35,36-40$ and $40+$ years), gender on the other hand was also categorized based on whether a respondent is a male or female, education level also captured three (3) categories which include Professional, first degree, and post graduate, whereas marital status of respondents was further categorized into three groups (married, single and divorced).

\subsection{Data Analysis}

Raw data obtained from the questionnaire administration is useless unless it is transformed into information for the purpose of decision making. Data analysis involved reducing the raw data into manageable size, developing summaries and applying statistical inferences. Consequently, the following steps were taken to analyze the data for the analysis. After the questionnaire administration, data obtained based on responses from respondents were cleaned and then coded using a five-point Likert scale as indicated already with the exception of the demographic variables. A strongly agreed answer, meant the respondent was allocated response strength of 5 points. A strongly disagree answer was also allocated response strength of 1 point. With this completed, the process of data analysis was done in three different levels. The first level was conducted for the demographic characteristics of the respondents using basic frequency distribution table. The second category of the analysis involved test of normality, test of sample adequacy, exploratory factor analysis, internal consistency analysis, summary of descriptive statistics and correlation analysis among employed variables. Finally, the third level of the analysis entailed a path analysis which focuses on estimating the path coefficients for the respective variables used in the conceptual mod- 
el so as to be able to compare and contrast the relationships and then eventually test the four hypotheses which have been proposed. In this case, the study employed a Hierarchical regression model which specifically shows the causal relationships amide the variables to be analyzed. All the various statistical tools employed in the data analysis were made possible by using SPSS version 20.0.

\subsection{Model Specification}

As indicated in the previous section, this current study utilizes the Hierarchical regression analysis to estimates the path coefficients in the other words the relationship between HRM practices, job satisfaction and employee turnover intentions. Specifically, the first and third variables are independent and response variables respectively whereas the second variable is also a response variable to the first variable but plays a mediating role between the first and third variables. The Hierarchical regression analysis is a way to show if variables of researcher's interest explain a statistical significance of the amount of variation in the response variable after accounting for all other variables. This is a framework for model comparison rather than a statistical method. In this framework, different linear regression models are formulated by adding explanatory variables to previous model at each step. In numerous cases the interest is to determine whether the newly included variable shows a significant improvement in the proportion of explained variance in the response variable by the model. Fundamentally, a multiple linear regression model with pexplanatory variables is mathematically formulated as:

$$
y_{i}=\beta_{o}+\beta_{1} x_{i 1}+\beta_{2} x_{i 2}+\cdots+\beta_{p} x_{i p}+\varepsilon
$$

where $x_{i j}$ represents the $i$ th observation on the $j$ th independent variable, $\beta_{o}$ is the intercept, $y_{i}$ is the $i$ th observation of the dependent variable whereas $\beta_{1}, \cdots, \beta_{p}$ captures the effect of the independent variables on the response variable.

Since Hierarchical regression models consist of series of linear regression models, the present study groups the series of regression models under the four main hypotheses in a Hierarchical manner. Thus in estimating the direct as well as the mediating effects among variables used in the study the following regression models were formulated from the proposed hypotheses. Considering the first hypothesis, the study postulated that, Human resource management (HRM) negatively influences employee turnover intentions. Based on this postulation we proposed the following regression model

$$
\text { Model 1: } \mathrm{ETI}_{i}=\beta_{o}+\beta_{1} \mathrm{HRM}_{i}+\varepsilon
$$

where ETI represents employee turnover intentions, HRM denotes human resource management practices. $\beta_{1}$ is expected to be negative in order to validate the first hypothesis.

In the case of the second hypothesis we anticipated that HRM practices positively affect job satisfaction. Thus relying on this conjuncture, we specified the following model also as: 
Model $2: \mathrm{JS}_{i}=\beta_{o}+\beta_{1} \mathrm{HRM}_{i}+\varepsilon$

where JB represents job satisfaction. $\beta_{1}$ is expected to be positive in order to support the second proposition.

With regards to the third conjuncture, the study based related literature speculated that, the higher the level of job satisfaction, the lesser the level of employee turnover intention. Thus base on this assertion the following regression model pertaining the relationship between job satisfaction and employee turnover intention is specified as follows;

$$
\text { Model 3: } \mathrm{ETI}_{i}=\beta_{o}+\beta_{1} \mathrm{JS}_{i}+\varepsilon
$$

where $\mathrm{ETI}_{i}$ and $\mathrm{JB}_{i}$ have already been explained. In the case of Model $3 \beta_{1}$ is expected to be negative in order to second the hypothetical relationship between employee turnover intentions and job satisfaction.

Finally, with regards to the fourth hypothesis, the study assessed the mediating effect of job satisfaction on the relationship between HRM practices and employee turnover intentions. Based on this hypothesis the following regression equation is formulated:

$$
\text { Model } 4: \mathrm{ETI}_{i}=\beta_{o}+\beta_{1} \mathrm{HRM}_{i}+\beta_{2} \mathrm{JS}_{i}+\varepsilon
$$

where $\beta_{2}$ captures the effect of job satisfaction as a mediating variable and in this model regarded as control variable, whereas $\beta_{1}$ measures the effect of HRM practices on employee turnover intentions.

Prior to estimating the hierarchical regression model based on the aforementioned conditions or postulates, the study employed Kaiser-Meyer-Olkin (KMO) and Cronbach's alpha to examine the adequacy of the sample and the suitability of data as well as how closely related a set of items are as a group. Sampling adequacy provides the researchers with information with respect to the grouping of survey items. Grouping items into a set of interpretable factors can accurately explain the constructs under study. Measures of sampling adequacy evaluate how strongly an item is correlated with other items. The sampling adequacy can be assessed by examining the KMO. This method of measuring sampling adequacy is only suggested when the cases to variable ratio are less than 1:5. It ranges from 0 to 1, while according to Tabachnick and Fidell (2001), 0.50 is considered suitable for factor analysis (FA). The Cronbach's alpha on the other hand provides a measure of the internal consistency of a test and is expressed as a number also between 0 and 1 as compared to the KMO. Internal consistency describes the extent to which all the items in attest measure the same construct thus connected to the inter-relatedness of the items within the test.

\section{Empirical Results and Discussion}

\subsection{Demographic Analysis}

Table 2 summarily gives the background characteristics of respondents that participated in the research survey. These characteristics from the table include gender, age, education, and marital status of respondents. The researcher sought 
Table 2. Demographic characteristics of respondents.

\begin{tabular}{cccc}
\hline Item & Scale & Frequency & Percentage \\
\hline Gender & Male & 58 & 31.0 \\
& Female & 128 & 69.0 \\
Age & $20-25$ years & 47 & 25.4 \\
& 26 - 30 years & 117 & 63.1 \\
& $31-35$ years & 2 & 0.8 \\
& 36 - 40 years & 16 & 8.5 \\
\multirow{3}{*}{ Education } & 40 years and above & 4 & 2.3 \\
& Professional & 6 & 3.1 \\
& First degree & 65 & 35.1 \\
& Postgraduate & 87 & 46.6 \\
& Others & 28 & 15.3 \\
& Married & 87 & 46.6 \\
Marital status & Single & 93 & 50.4 \\
& Divorced & 6 & 3.1 \\
\hline
\end{tabular}

to find out the gender distribution of respondents involved in the study. Results from Table 3 established that $31.0 \%$ of the respondents are males as compared to $69.0 \%$ representing the majority who were females. Notably, females prevail males from the total number of respondents in the study. Following the gender distribution was age distribution of participants. In lieu to this, the study intended to determine the age of the target respondents involved in the research. The findings illustrate that $25.4 \%$ of the respondents are between 20 and 25 years, $63.1 \%$ between 26 to 30 years, $0.8 \%$ were between $31-35$ years, $8.5 \%$ also between 36 - 40 years and $2.3 \%$ of the total number of respondents were 40 years and above. Thus, the findings indicate that majority of the respondents are between 26 - 30 years followed by those who were between $20-25$ years. We additionally intended to determine the marital status of the target respondents sampled for the study. It is evidenced that, $46.6 \%$ of the respondents were married, $50.4 \%$ are single whereas only $3.1 \%$ representing the minority had divorced. In the context of respondents' level of education, results from Table 2 shows that, only of $3.1 \%$ of the sample are professionals, $35.1 \%$ are first degree holders whilst $46.6 \%$ are also postgraduates. $15.3 \%$ on the other indicated they educated but to other levels apart from the once given. The findings per distribution of respondents with respect to education insinuates that majority of the respondents sampled for the study are relatively educated to provide responses on topic under discussion.

\subsection{Test for Data Adequacy}

The Kaiser-Meyer-Olkin (KMO) measure of sampling adequacy and Bartlett's 
Table 3. KMO and Bartlett's test results.

\begin{tabular}{cccc}
\hline Variables & No of items & $\begin{array}{c}\text { KMO } \\
\text { test value }\end{array}$ & $\begin{array}{c}\text { Bartlett's Test } \\
\text { of Sphericity }\end{array}$ \\
\hline HRM practices & 13 & 0.784 & $356.160(0.000)^{* * *}$ \\
Job satisfaction & 17 & 0.937 & $402.101(0.000)^{* * *}$ \\
Employee turnover intentions & 8 & 0.804 & $465.179(0.000)^{* * *}$ \\
\hline
\end{tabular}

Note: Values in parenthesis are probability values, ${ }^{* * *}$ represents the significant level at $1 \%$.

test of Sphericity tests help to indicate whether the data per the various constructs and their respective measures used in this study are suitable for structure reduction. Specifically, the KMO test is a statistic indicating the proportion of variance that might be caused by some underlying factors. From Table 3, the test value of the KMO regarding HRM practices is obtained as $0.784,0.937$ for Job satisfaction as a mediating variable whereas that of the response construct is 0.804 . The corresponding KMO test values of the various constructs are very high (closer to 1 ) and hence gives the general indication that a substantial proportion of variance of about $78.4 \%, 93.7 \%$ and $80.4 \%$ respectively have been explained by the constructs under discussion. Also, the values of the KMO test gives an indication that the sample data for the various constructs are adequate for a factor analysis. Additionally, the Bartlett's test of Sphericity tests the hypothesis that the correlation matrix is an identity matrix. This gives the indication that the variables within a specific construct are unrelated and therefore unsuitable for structure detection. The Bartlett's test of Sphericity test from Table 4 correspondingly for the aforementioned constructs gives p-values less than the level of significance leading to rejection of the hypothesis. This therefore implies that, the variables in the correlation matrix are related and hence suitable for structure reduction (factor analysis). In the nutshell these tests (Kaiser-Meyer-Olkin (KMO) and Bartlett's test) show that, the data for each construct used in the study is adequate enough for structure reduction or factor analysis. Table 3 shows results from the KMO and Bartlett's test.

\subsection{Exploratory Factor Analysis and Internal Consistency}

After confirming that data for pertaining each construct is adequate enough for factor analysis using the KMO and Bartlett's tests, it is deemed necessary to investigate the validity and reliability of HRM practices, job satisfaction and employee turnover intensions. In order to assess the validity and reliability of the various constructs as mentioned, the exploratory factor analysis (EFA) as well as the internal consistency analysis were together employed. The exploratory factor analysis together with the internal consistency analysis enhances the development of the aforementioned scales. The former approach (EFA) encompasses primary items within the Likert scales, Kaiser's rule (eigenvalue $>1$ ) or/and scree plots to decide factor numbers extracted, factor loadings estimated by principal component analysis (PCA) and factor rotation with orthogonal rotation and 
Table 4. Validity and reliability of constructs.

\begin{tabular}{|c|c|c|c|c|c|c|}
\hline Construct & Items & $\begin{array}{l}\text { Factor } \\
\text { loadings }\end{array}$ & $\begin{array}{c}\text { No. of items } \\
\text { extracted }\end{array}$ & Eig.val. & $\begin{array}{c}\text { Accumulative } \\
\text { explained } \\
\text { variance }(\%)\end{array}$ & $\begin{array}{l}\text { Cronbach's } \\
\text { alpha }\end{array}$ \\
\hline \multirow[t]{6}{*}{ HRM practices } & & & 5 & 8.350 & 23.768 & 0.958 \\
\hline & HRMp7 & 0.848 & & & & \\
\hline & HRMp12 & 0.983 & & & & \\
\hline & HRMp10 & 0.819 & & & & \\
\hline & HRMp1 & 0.789 & & & & \\
\hline & HRMp3 & 0.733 & & & & \\
\hline \multirow[t]{11}{*}{ Job satisfaction } & & & 10 & 8.917 & 47.762 & 0.955 \\
\hline & JB1 & 0.782 & & & & \\
\hline & JB10 & 0.830 & & & & \\
\hline & JB12 & 0.985 & & & & \\
\hline & JB15 & 0.880 & & & & \\
\hline & JB8 & 0.873 & & & & \\
\hline & JB3 & 0.817 & & & & \\
\hline & JB6 & 0.868 & & & & \\
\hline & JB17 & 0.883 & & & & \\
\hline & JB14 & 0.860 & & & & \\
\hline & JB4 & 0.781 & & & & \\
\hline \multirow[t]{9}{*}{$\begin{array}{c}\text { Employee } \\
\text { turnover intentions }\end{array}$} & & & 8 & 8.240 & 70.683 & 0.965 \\
\hline & ETI1 & 0.724 & & & & \\
\hline & ETI2 & 0.749 & & & & \\
\hline & ETI3 & 0.766 & & & & \\
\hline & ETI4 & 0.826 & & & & \\
\hline & ETI5 & 0.813 & & & & \\
\hline & ETI6 & 0.823 & & & & \\
\hline & ETI7 & 0.798 & & & & \\
\hline & ETI8 & 0.815 & & & & \\
\hline
\end{tabular}

Note: All the items as defined in the Appendix from Table A1.

varimax. The latter approach (internal consistency analysis) on the other hand employed the Cronbach's alpha coefficient. Results from Table 4 reveals that among the thirteen (13) items employed to measure HRM practices only five (5) measurement items were retained based on their high factor loadings. HRM practices an independent variable in this case explained $23.768 \%$ of the variance for the items and had eigenvalue of 8.350. The Cronbach's alpha was 0.958 for the factor with respect the six (6) items retained. Additionally, after running severally repeated the date analysis with varimax rotation and assessing changes 
in eigenvalues, ten (10) items of seventeen (17) measuring job satisfaction loaded adequately. The ten items of job satisfaction had an eigenvalue of 8.917 and explained variance of $47.762 \%$ for the retained items. The Cronbach's alpha for this construct was also 0.955 .

In the case of employee turnover intentions none of the eight (8) items assumed to measure the aforementioned construct was exempted since their factor loadings were evidenced to be greater than the threshold of 0.7 . This construct with respect to its measurement items had eigenvalue of 8.240 and explained 70.683 percent of the variance within the items. The Cronbach's alpha per this construct on the other hand was 0.965. Summarily, the analysis regarding the EFA and internal consistency shows that the scales employed in the study are characterized by a very good construct validity and internal consistency.

\subsection{Test of Normality}

Table 5 presents the results based on the normality test for all the constructs employed in the study with respect to their respective number of measurement items as revealed by the EFA approach. The normality test is conducted to determine the distribution of the data per analyzed variables. It must be noted that the type of analytical technique or process used to analyze data is dependent on the distribution of the data. When the data is skewed positively or negatively; the researcher must employ a non-parametric test whiles a normally distributed data (Gaussian distribution) requires parametric test analysis. The test criteria as suggested by Stebbins (2001) are to obtain a Shapiro Wilks and Kolmogorov-Smirnov test values in excess of 0.5 . From Table 5 , the analyzed data shows that all the parameters obtained a p-value in excess of 0.5 thus, this is an indication that the data pertaining the various constructs are normally distributed hence the justification for the use of parametric test procedure for the entire analysis.

\subsection{Descriptive Statistics, Correlation Matrix and Colinearity Test}

A brief summary of the descriptive statistics is presented in Table 6. Results pertaining the descriptive statistics reveal HRM practices as the construct with the highest mean of 3.847 with a standard deviation of 0.725 followed by Employee turnover intentions which recorded a mean value of 3.53 and a dispersion value of 0.842 . Job satisfaction which serves as the mediating variable had the

Table 5. Test of normality of constructs.

\begin{tabular}{cccccc}
\hline \multirow{2}{*}{ Construct } & No. of items & \multicolumn{2}{c}{ Kolmogorov-Smirnov $^{\mathrm{a}}$} & \multicolumn{2}{c}{ Shapiro-Wilk } \\
\cline { 3 - 6 } & extracted & Statistic & Sig. & Statistic & Sig. \\
\hline HRM practices & 6 & $0.312^{* * *}$ & 0.000 & $0.721^{\star * *}$ & 0.000 \\
Job satisfaction & 10 & $0.337^{* * *}$ & 0.000 & $0.652^{* * *}$ & 0.004 \\
Employee turnover intentions & 8 & $0.262^{* * *}$ & 0.025 & $0.716^{* * *}$ & 0.000 \\
\hline
\end{tabular}

Note: Sig. represents Significant value whereas ${ }^{* * *}$ represents the significance level at $1 \%$. 
Table 6. Summary of descriptive statistics, correlation matrix and collinearity test.

\begin{tabular}{lccccccc}
\hline \multicolumn{1}{c}{ Variable } & Mean & SD & 1 & 2 & 3 & VIF & Tolerance \\
\hline $\begin{array}{l}\text { 1) HRM practices } \\
\text { 2) Job satisfaction }\end{array}$ & 3.847 & 0.725 & 1.000 & - & - & 8.252 & 0.471 \\
$\begin{array}{l}\text { 3) Employee turnover } \\
\text { intentions }\end{array}$ & 3.151 & 0.693 & $0.330^{* *}$ & 1.000 & - & 1.917 & 0.552 \\
\hline
\end{tabular}

Note: ${ }^{*}$ and ${ }^{\star *}$ represents $10 \%$ and $5 \%$ significance levels respectively.

least mean value of 3.151 with a standard deviation of 0.72 . Table 6 further reports correlation analysis results amid the employed constructs in the study. There is an indication from the correlation matrix that, there exist positive linear relationship between job satisfaction and HRM practices whereas employee turnover intention is negatively related with job satisfaction and HRM practices. The nature of relationships amid the various constructs as Table 6 reveals support the first three hypotheses proposed in the study. Still on the correlation coefficients can evidenced all the correlation values between the analyzed constructs are far less than less than 0.7 indicating no presence of multicolinearity. With the absence of multicolinearity amid based on the results from the correlation values the study further employed the tolerance and variance inflation factor (VIF) as robustness check for multicolinearity. The VIF values are much less than 10 whereas that of tolerance on the other hand is more than 0.2 . This as a result leads to the rejection of the assertion that multicolinearity is likely occur amid employed variables and hence supports the outcome of the correlation coefficients.

\subsection{Path Analysis}

After preliminarily confirming that, the scales employed in this current study are adequate for structure reduction, characterized by a very good construct validity and internal consistency, as well as normally distributed with no multicolinearity, it is deemed important for authors order to estimate path coefficients reference to the model formulated in the study, the authors hypothesized that job satisfaction mediated the affiliation between HRM practices and employee turnover intentions. With the main aim of scrutinizing whether the mediation role job satisfaction matter in the liaison between HRM practices and employee turnover intentions, we employed a four-step model approach. First, using a linear regression model, HRM practices must be shown to predict employee turnover intentions. Secondly, HRM practices must be shown to predict job satisfaction in another linear regression model. Third, using a linear regression model, job satisfaction must similarly be able to predict employee turnover intentions. Finally, the relationship between HRM practices and employee turnover intentions must be enhanced significantly or eliminated after controlling for job satisfaction as a mediating variable. The outcomes from the four step revealed that job satisfaction met the conditions for mediation as follows; 1) HRM practices (HRMp) predicted employee turnover intentions resulting into a standardized regression 
coefficient $\operatorname{HRMp}(\beta)=-0.641(\mathrm{t}=20.542, \mathrm{p}<0.000)$ and the amount variance explained by HRM practices is $\left.\mathrm{R}^{2}=0.509(\mathrm{~F}=408.102, \mathrm{P}<0.000) ; 2\right)$ HRM practices predicted job satisfaction, leading to a standardized regression coefficient of $\operatorname{HRMp}(\beta)=0.721(\mathrm{t}=27.852, \mathrm{p}<0.000)$ with the amount of variance explained by $\mathrm{HRM}$ practices $\left.\mathrm{R}^{2}=0.643(\mathrm{~F}=771.557, \mathrm{P}<0.000) ; 3\right)$ job satisfaction on the other hand was able to predict employee turnover intentions (ETI) resulting into a standardized regression coefficient $\mathrm{JB}(\beta)=-0.297(\mathrm{t}=10.379, \mathrm{p}$ $<0.000)$ and the amount of variabilities explained by job satisfaction $\mathrm{R}^{2}=0.664$ $(\mathrm{F}=508.809, \mathrm{P}<0.000)$; and the effect of HRM practices on employee turnover intentions (ETI) was enhanced after controlling for job satisfaction (JS) as mediating variable leading to a unvarying regression coefficient $\operatorname{HRMp}(\beta)=0.509$ $(\mathrm{t}=15.375, \mathrm{p}<0.000)$ and standardized coefficient $\mathrm{JS}(\beta)=0.710(\mathrm{t}=29.390, \mathrm{p}<$ 0.000 ) with a joint amount of variance explained by both HRM practices and job satisfaction $\mathrm{R}^{2}=0.561(\mathrm{~F}=248.550, \mathrm{p}<0.000)$. Table 7 outlines the aforementioned reported results. The outcomes from the four estimating regression models suggest that there has been an enhanced mediation due to the fact that HRM practice has significantly more effect on employee turnover intentions when job satisfaction as added to the model. Thus, the fourth hypothesis which states that job satisfaction mediates the affiliations between HRM practices and employee turnover intentions is supported. The four significant standardized regression coefficients as illustrated in Table 7 summarily reveal three main significant paths in relation to employee turnover intentions. The first is from HRM practices to employee turnover intentions (HRMp $\rightarrow$ ETI), second is from HRM practices to job satisfaction (HRMp $\rightarrow$ JS) whereas the third is from job satisfaction to employee turnover intentions (JB $\rightarrow$ ETI). The three significant path coefficients as afore-stated supported hypotheses 1,2 and 3 in the sense that: 1) HRM practices was evidenced to have a negative effect on employee turnover intentions meaning Human resource management (HRM) negatively influences employee turnover intentions; 2) HRM practices have a positive relationship with job satisfaction and 3) job satisfaction negatively influences employee turnover intentions which give the implication that the higher the level of job satisfaction, the lesser the level of employee turnover intention. These outcomes are in consonant with a bulk of literature which includes [24] [26] [27] [30] [32] [33] [34] [36] just to mention a few.

Table 7. Test of mediating relationship between HRM practices and Employee turnover intentions.

\begin{tabular}{|c|c|c|c|c|c|c|c|c|}
\hline Model/Step & Predictors & Criterion & $\mathrm{R}$ & R-sq. & R-sq. adj. & F-test & $\beta$ & t-test value \\
\hline 1 & HRMp & ETI & 0.714 & 0.509 & 0.499 & $408.102^{* * *}$ & -0.641 & $20.542^{* * *}$ \\
\hline 2 & HRMp & JB & 0.802 & 0.643 & 0.640 & $771.557^{\star * *}$ & 0.721 & $27.852^{\star * *}$ \\
\hline 3 & JS & ETI & 0.815 & 0.664 & 0.661 & $508.809^{* * *}$ & -0.297 & $10.379^{* * *}$ \\
\hline 4 & $\begin{array}{l}\text { HRMp } \\
\text { JS }\end{array}$ & ETI & 0.749 & 0.561 & 0.558 & $248.550^{* * *}$ & $\begin{array}{l}0.509 \\
0.710\end{array}$ & $\begin{array}{l}15.735^{* * *} \\
29.390^{* * *}\end{array}$ \\
\hline
\end{tabular}

Note: R, R-sq. and R-sq. adj. represents correlation coefficient, correlation coefficient squared and adjusted correlation coefficient squared respectively. HRMp, JS and ETI also means human resource management practices, job satisfaction and employee turnover intentions respectively. ${ }^{* * *}$ mean significance at $1 \%$ level. 
Considering the effect of HRM practices on employee turnover intentions, the prior path to be exact HRMp impacts employee turnover intentions indirectly through job satisfaction, where job satisfaction plays an intervening role (Figure 2). Hence, job satisfaction is likely to serve as a mediator in affecting employee turnover intentions. On the other hand this can also mean that, HRM practices probably may have indirect influence on employee turnover intentions, while job satisfaction may directly impact employee turnover intentions. This seconds the results revealed by [33] [53] [56] who evidenced job satisfaction as mediator between specific HRM practices and turnover intentions.

\section{Conclusions}

Though numerous researches have established the liaison between HRM practices and employee turnover intentions, the point of this exploration is cross-examined the intervening or mediating role of job satisfaction among the affiliation amid HRM practices and employee turnover intentions using information from a developing country Ghana. This current study specifically targeted the top ten private organization firms in the country as subjects of study. These top ten private companies or organizations included Newmont Golden Ridge Limited, Ghana Oil Company, Goldfields Ghana Limited, MTN group, Vivo Energy Ghana, Unibank Ghana limited, Mutlipro Limited Ghana, Nordea Capital limited, Justmoh Construction Limited and Total Petroleum Ghana. Specifically, 20 respondents which include both senior and junior staff were randomly selected from each firm summing up to a sample of 200 respondents of the study. The study upon organizing the data base on responses from respondents attained a response rate of $93.0 \%$ meaning 186 out of 200 respondents

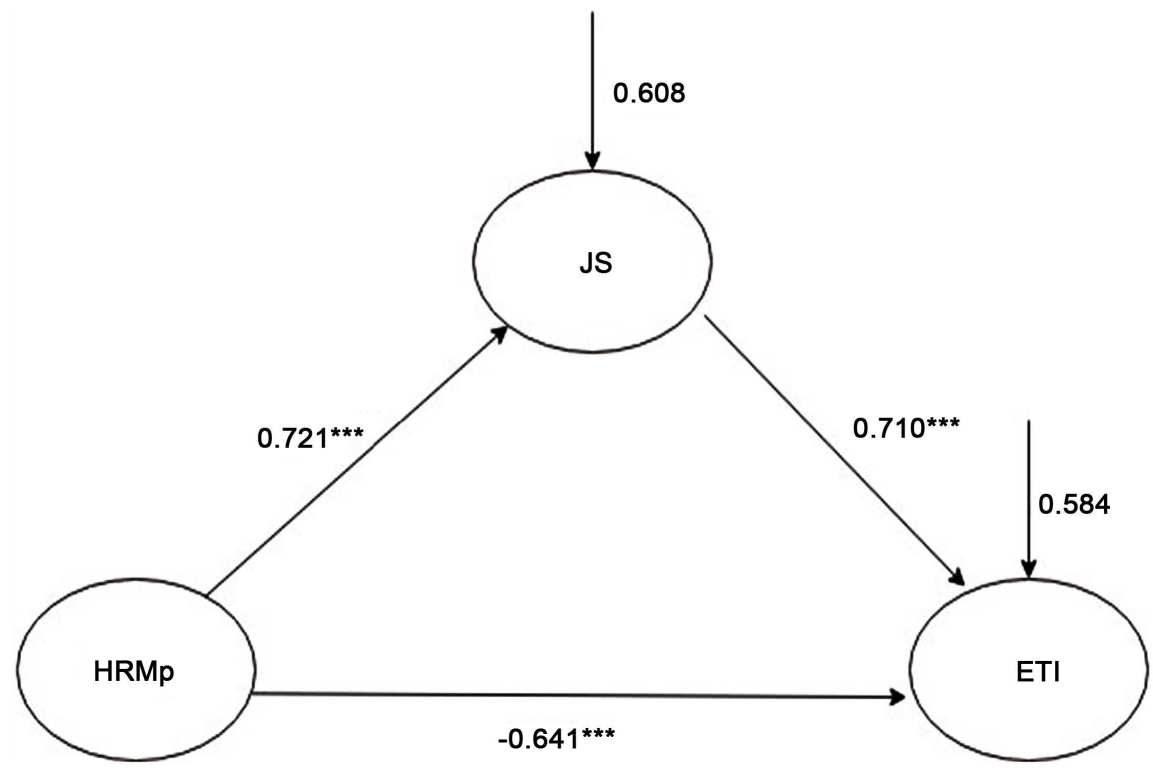

Figure 2. Estimated path diagram showing the mediating affiliation among HRM practices, job satisfaction and employee turnover intentions with standardized parameter estimates. 
were able to answer questionnaires completely without any errors. Preliminarily, the data employed in the study was evidenced to follow the normal distribution, adequate for structure reduction, characterized by a very good construct validity and internal consistency without any issues of multicolinearity. With regards to the proposed conceptual model of the study, four different regression models were estimated in order to examine the mediating relationship amid aforementioned constructs. The current study established a positive relationship between HRM practices and job satisfaction, additionally established a negative connection between HRM practices and employee turnover intentions as well as a negative affiliation between job satisfaction and employee turnover intentions. Moreover, the study revealed that job satisfaction mediates efficiently the relationship among HRM practices and employee turnover intentions. Also HRM practices directly impact employee turnover intentions and indirectly influence employee turnover intentions through the intervening or mediating role of job satisfaction. In the nut shell the study identified a mediator of job satisfaction within the association between HRM practices and employee turnover intentions.

The practical application of the study demonstrates that HRM practices and job satisfaction are two vital predictors of employee turnover intentions and that job satisfaction takes a mediating role in the affiliation between HRM practices and employee turnover intentions. Of all the elements that contribute to successful HRM practices, commitment and action of managerial staff in various private organizations are the most important. The reason behind this is that, regardless of commitment and action, HRM practices are almost sure to fail. Development pertaining job satisfaction therefore needs senior management as well as managers to show visibly the strongest commitment and action on consistent basis. Nevertheless, the commitment and actions of managers towards employees to job satisfaction may involve certain components of HRM practices. The positive relationship between HRM practice and job satisfaction provides a wisdom way on how an organization can motivate an employee to work efficiently. In addition, the negative relationship flanked by HRM practices and employee turnover intentions is vividly enlightened the necessities of providing good supervision as well as training in order to minimize turnover rates of employees. Besides, job satisfaction is directly influenced on turnover with negative liaison implying that, job satisfaction can minimize employee turnover intentions when the job satisfaction of employees is high.

Additionally, since the path analysis can be used to examine the possible causations among the variables used in the study, measurement inaccuracy may be neglected of which the structural equation model (SEM) takes this issue into consideration. Thus in the case of future research, SEM can be employed to investigate the complex affiliations among these three constructs so as to establish a more better model. Further, a factor like organizational trust together with HRM practices and job satisfaction may influence employee turnover intentions and is worth investigating. Future studies in similar field should also investigate 
the effect of Human Resource Practices on the Employee Turnover Intentions in both, the public and private sector organizations since this current study only focused on private organizations.

\section{Conflicts of Interest}

Authors of this study declare no conflicts of interest.

\section{References}

[1] Thwala, D.W., Ajagbe, A.M., Long, C.S., Bilau, A.A. and Enegbuma, W.I. (2012) Sudanese Small and Medium Sized Construction Firms: An Empirical Survey of Job Turnover. Journal of Basic, Applied Social Research, 2, 7414-7420.

[2] Price, J.L. (2001) Reflections on the Determinants of Voluntary Turnover. International Journal of Manpower, 22, 600-624. https://doi.org/10.1108/EUM0000000006233

[3] Abdullah, A., Bilau, A.A., Enegbuma, W.I., Ajagbe, A.M. and Ali, K.N. (2011) Evaluation of Job Satisfaction and Performance of Employees in Small and Medium Sized Construction Firms in Nigeria. Proceedings of 2 nd International Conference on Construction and Project Management, 15, 225-229.

[4] Daniels, S.R., Wang, G., Lawong, D. and Ferris, G.R. (2018) Collective Assessment of the Human Resources Management Field: Meta-Analytic Needs and Theory Development Prospects for the Future. Human Resource Management Review, 27, 8-25. https://doi.org/10.1016/j.hrmr.2016.09.002

[5] Gadi, P.D. and Kee, D.H.M. (2018) Human Resource Management Practices and Turnover Intention: The Mediating Role of Perceived Organizational Support in Tertiary Institutions in Nigeria. International Journal of Engineering and Technology, 7, 715-722.

[6] Fajana, S., Owoyemi, O., Elegbede, T. and Gbajumo-Sheriff, M. (2011) Human Resource Management Practices in Nigeria. Journal of Management and Strategy, 2, 57. https://doi.org/10.5430/jms.v2n2p57

[7] Hackman, J.R. and Oldham, G.R. (1975) Development of the Job Diagnostic Survey. Journal of Applied Psychology, 60, 159-170 http://www.jstor.org/stable/pdf/3000143.pdf?refreqid=excelsior\%3A60f953d9a44cfd ec3a63ff1435f2b286 https://doi.org/10.1037/h0076546

[8] Amah, O.E. (2009) Job Satisfaction and Turnover Intention Relationship: The Moderating Effect of Job Role Centrality and Life Satisfaction. Research and Practice in Human Resource Management, 17, 24-35.

[9] Khilji, S. and Wang, X. (2007) New Evidence in an Old Debate: Investigating the Relationship between HR Satisfaction and Turnover. International Business Review, 16, 377-395. https://doi.org/10.1016/j.ibusrev.2006.12.005

[10] Morrow, P. and McElroy, J. (2007) Efficiency as a Mediator in Turnover: Organizational Performance Relations. Human Relations, 60, 827-849. https://doi.org/10.1177/0018726707080078

[11] Liu, S. and Onwuegbuzie, A.J. (2012) Chinese Teachers' Work Stress and Their Turnover Intention. International Journal of Educational Research, 53, 160-170. https://doi.org/10.1016/j.ijer.2012.03.006

[12] Maneesatitya, M. and Fongsuwan, W. (2014) Structural Equation Model of Va- 
riables Affecting Turnover Intentions on Bangkok's Information Technology Career Professionals. Research Journal of Business Management, 8, 453-463. https://doi.org/10.3923/rjbm.2014.453.463

[13] Gould-Williams, J.S., Bottomley, P., Redman, T., Snape, E., Bishop, D.J., Limpantgul, T. and Mostafa, A.M.S. (2013) Civic Duty and Employee Outcomes: Do High Commitment Human Resource Practices and Work Overload Matter? Public Administration, 92, 937-953. https://doi.org/10.1111/padm.12019

[14] Steijn, B. (2002) HRM and Job Satisfaction in the Dutch Public Sector. Paper Presented at the EGPA Conference in Potsdam, Study Group on Public Personnel Policies.

[15] Bradley, S., Petrescu, A. and Simmons, R. (2004) The Impacts of Human Resource Management Practices and Pay Inequality on Workers' Job Satisfaction. Paper Presented at the Western Economic Association 79th Annual Conference, Vancouver.

[16] Huselid, M.A. (1995) The Impact of Human Resource Management Practices on Turnover, Productivity, and Corporate Financial Performance. Academy of Management Journal, 38, 635-672.

[17] Boselie, P., Dietz, G. and Boon, C. (2005) Commonalities and Contradictions in HRM and Performance Research. Human Resource Management Journal, 15, 67-94. https://doi.org/10.1111/j.1748-8583.2005.tb00154.x

[18] Combs, J., Liu, Y., Hall, A. and Ketchen, D. (2006) How Much to High-Performance Work Practices Matter? A Meta-Analysis of Their Effects on Organizational Performance. Personnel Psychology, 59, 501-528. https://doi.org/10.1111/j.1744-6570.2006.00045.x

[19] Blau, P.M. (1964) Exchange and Power in Social Life. Wiley, New York.

[20] Wright, P.M., Gardner, T.M. and Moynihan, L.M. (2003) The Impact of HR Practices on the Performance of Business Units. Human Resource Management Journal, 13, 21-36. https://doi.org/10.1111/j.1748-8583.2003.tb00096.x

[21] Sun, L.Y., Aryee, S. and Law, K.S. (2007) High-Performance Human Resource Practices, Citizenship Behavior, and Organizational Performance: A Relational Perspective. Academy of Management Journal, 50, 558-577. https://doi.org/10.5465/amj.2007.25525821

[22] Mayer, R.C. and Davis, J.H. (1999) The Effect of the Performance Appraisal System on Trust for Management: A Field Quasi-Experiment. Journal of Applied Psychology, 84, 123-136. https://doi.org/10.1037/0021-9010.84.1.123

[23] Sareen, B. (2018) Relationship between Strategic Human Resource Management and Job Satisfaction. International Journal of Current Research in Life Sciences, 7, 1229-1233.

[24] Khan, R.A., Arif, A. and Rehman, A. (2015) Impact of Training and Development Practices on Employees' Job Satisfaction at Pakistan International Airline. Journal of Business Studies, 11, 145-159.

[25] Chaudhry, N.S. and Bhaskary, P. (2016) Training and Development and Job Satisfaction in Education Sector. Journal of Resource Development and Management, $16,42-45$.

[26] Nagaraju, B. and Archana. M.V. (2015) Job Satisfaction through Training and Development Program. A Case Study of J. K Tyre Ltd., Mysore. Journal of Business and Management, 17, 5-13.

[27] Ramadhani, R.M. (2017) The Effect of Human Resource Management Practices on Employees' Job Satisfaction in Monduli District Council. Doctoral Dissertation, The 
Open University of Tanzania, Dar es Salaam, Tanzania.

[28] Costen, W.M. and Salazar, J. (2011) The Impact of Training and Development on Employees' Job Satisfaction, Loyalty and Intent to Stay in the Lodging Industry. Journal of Human Resource in Hospitality and Tourism, 10, 273-284. https://doi.org/10.1080/15332845.2011.555734

[29] Salisu, J.B., Chinyio, E. and Suresh. S. (2015) The Impact of Compensation on the Job Satisfaction of Public Sector Construction Workers of Jigawa State of Nigeria. The Business and Management Review, 6, 282-296.

[30] Yaseen, A. (2013) Effect of Compensation Factors on Employees' Job Satisfaction: A Study of Doctors' Dissatisfaction in Punjab. International Journal of Human Resource Studies, 3, 142-157. https://doi.org/10.5296/ijhrs.v3i1.3351

[31] Tessema, M.T., Ready, K.J. and Embaye, A.B. (2013) The Effects of Employee Recognition, Pay, and Benefits on Job Satisfaction: Cross Country Evidence. Journal of Business and Economics, 4, 1-12.

[32] Nawab, S. and Bhatti, K.K. (2011) Influence of Employee Compensation on Organizational Commitment and Job Satisfaction: A Case Study of Educational Sector of Pakistan. International Journal of Business and Social Science, 2, 25-32.

[33] Kampkotter, P. (2016) Performance Appraisal and Job Satisfaction. The International Journal of Human Resource Management, 28, 750-774. https://doi.org/10.1080/09585192.2015.1109538

[34] Ray, S. and Ray, I.A. (2011) Human Resource Management Practices and Its Effect on Employees' Job Satisfaction: A Study on Selected Small and Medium Sized Iron and Steel Firms in India. Public Policy and Administration Research, 1, 22-34.

[35] Wan Omar, W.A. and Hussin, F. (2013) Transformational Leadership Style and Job Satisfaction Relationship: A Study of Structural Equation Modeling (SEM). International Journal of Academic Research in Business and Social Sciences, 3, 346-365.

[36] Kithuku, M.V. (2012) Effect of performance Appraisal on Job Satisfaction at Kenya Commercial Bank. Master's Dissertation, University of Nairobi, Nairobi.

[37] Wang, Y.D., Yang, C. and Wang, K.Y. (2012) Comparing Public and Private Employees' Job Satisfaction and Turnover. Public Personnel Management, 41, 557-573. https://doi.org/10.1177/009102601204100310

[38] Lambert, E.G., Reynolds, K.M., Paoline III, E.A. and Watkins, R.C. (2004) The Effects of Occupational Stressors on Jail Staff Job Satisfaction. Journal of Crime and Justice, 27, 1-32. https://doi.org/10.1080/0735648X.2004.9721627

[39] Schwepker, C.H. (2001) Ethical Climate's Relationship to Job Satisfaction, Organizational Commitment, and Turnover Intention in the Sales Force. Journal of Business Research, 54, 39-52. https://doi.org/10.1016/S0148-2963(00)00125-9

[40] Aydogdu, S. and Asikgil, B. (2011) An Empirical Study of the Relationship among Job Satisfaction, Organizational Commitment and Turnover Intention. International Review of Management and Marketing, 1, 43-53.

[41] Kabungaidze, T., Mahlatshana, N. and Ngirande, H. (2013) The Impact of Job Satisfaction and Some Demographic Variables on Employee Turnover Intentions. International Journal of Business Administration, 4, 53-65. https://doi.org/10.5430/ijba.v4n1p53

[42] Arekar, K., Jain, R., Desphande, B. and Sherin, P. (2016) Relationship between Individual and Structural Determinants on Job Satisfaction-Analysis of Employee Turnover in the Indian Context. The Journal of Developing Areas, 50, 387-398. https://doi.org/10.1353/jda.2016.0149 https://muse.jhu.edu/article/626816/summary 
[43] Price, J.L. (1977) The Study of Turnover. Iowa State University Press, Ames, IA.

[44] Staw, B.M. (1980) The Consequences of Turnover. Journal of Occupational Behaviour, 1, 253273.

[45] Blau, P.M. (1987) Social Exchange Theory. http://www.tut.ee/public/m/mart-murdvee/EconPsy/5/6. EconPsy Social exchan ge.pdf

[46] Cropanzano, R. and Mitchell, M.S. (2005) Social Exchange Theory: An Interdisciplinary Review. Journal of Management, 31, 874-900. https://doi.org/10.1177/0149206305279602

[47] Mobley, W.H. (1982) Employee Turnover: Causes, Consequences, and Control. Reading, Addison Wesley, MA.

[48] Lee, T.W., Mitchell, T.R., Holtom, B.C., McDaniel, L. and Hill, J.W. (1999) Theoretical Development and Extension of the Unfolding Model of Voluntary Turnover. Academy of Management Journal, 42, 450-462. https://doi.org/10.5465/257015

[49] Muchinsky, P.M. and Tuttle, M.L. (1979) Employee Turnover: An Empirical and Methodological Assessment. Journal of Vocational Behavior, 14, 43-77. https://doi.org/10.1016/0001-8791(79)90049-6

[50] Porter, L.W. and Steers, R.M. (1973) Organizational, Work, and Personal Factors in Employee Turnover and Absenteeism. Psychological bulletin, 80, 151-176. https://doi.org/10.1037/h0034829

[51] Alsaraireh, F., Griffin, Q.M.T., Ziehm, S.R. and Fitzpatrick, J.J. (2014) Job Satisfaction and Turnover Intention among Jordanian Nurses in Psychiatric Units. International Journal of Mental Health Nursing, 23, 460-467.

https://doi.org/10.1111/inm.12070

[52] Peng, J., Li, D., Zhang, Z., Tian, Y., Miao, D., Xiao, W. and Zhang, J. (2014) How Can Core Self-Evaluations Influence Job Burnout? The Key Roles of Organizational Commitment and Job Satisfaction. Journal of Health Psychology, 21, 50-59. https://doi.org/10.1177/1359105314521478

[53] Sousa-Poza, A. and Henneberger, F. (2004) Analyzing Job Mobility with Job Turnover Intentions: An International Comparative Study. Journal of Economic Issues, 38, 113-137. https://doi.org/10.1080/00213624.2004.11506667

[54] Joseph, D., Ng, K.Y., Koh, C. and Ang, S. (2007) Turnover of Information Technology Professionals: A Narrative Review, Meta-Analytic Structural Equation Modeling, and Model Development. MIS Quarterly, 31, 547-577. https://doi.org/10.2307/25148807

[55] Choudhury, D. and Mishra, S. (2011) Compensation-Satisfaction Correlation at Workplace: A Study on BPOs at Orissa. International Journal of Business and Management Tomorrow, 1, 1-15. https://yen.com.gh/

[56] Danneels, E. and Kleinschmidtb, E.J. (2001) Product Innovativeness from the Firm's Perspective: Its Dimensions and Their Relation with Project Selection and Performance. Journal of Product Innovation Management: An International Publication of the Product Development and Management Association, 18, 357-373. https://doi.org/10.1111/1540-5885.1860357

[57] Jiménez, P. (2008) Profilanalyse der Arbeitszufriedenheit [Profile Analysis of Job Satisfaction]. Manual Wiener Testsystem, Mödling, Austria, Schuhfried.

[58] Jacobs, E.J. and Roodt, G. (2008) Organizational Culture of Hospitals to Predict Turnover Intentions of Professional Nurses. Journal of Interdisciplinary Health Sciences, 13, 63-78. https://doi.org/10.4102/hsag.v13i1.258 


\section{Appendix}

Table A1. Summary of constructs and measurement items.

\begin{tabular}{|c|c|c|}
\hline Construct & Indicator & Measurement items \\
\hline \multirow[t]{13}{*}{$\begin{array}{c}\text { Human Resource } \\
\text { Management } \\
\text { Practices }\end{array}$} & HRMp1 & $\begin{array}{l}\text { This organization's corporate communications } \\
\text { are frequent enough }\end{array}$ \\
\hline & HRMp2 & $\begin{array}{l}\text { This organization's corporate communications } \\
\text { are detailed enough }\end{array}$ \\
\hline & HRMp3 & $\begin{array}{l}\text { I have a good understanding of how this } \\
\text { organization is doing financially }\end{array}$ \\
\hline & HRMp4 & I can trust what this organization tells me \\
\hline & HRMp5 & This organization treats me like a person, not a number \\
\hline & HRMp6 & $\begin{array}{l}\text { This organization gives me enough recognition } \\
\text { for work that is well done }\end{array}$ \\
\hline & HRMp7 & Staffing levels are adequate to provide quality products/services \\
\hline & HRMp8 & Quality is a top priority with this organization \\
\hline & HRMp9 & Safety is a top priority with this organization \\
\hline & HRMp10 & My employer enables a culture of diversity \\
\hline & HRMp11 & I like the people I work with at this organization \\
\hline & HRMp12 & At this organization, employees have fun at work \\
\hline & HRMp13 & $\begin{array}{l}\text { I feel I can express my honest opinions without fear } \\
\text { of negative consequences }\end{array}$ \\
\hline \multirow[t]{17}{*}{ Job Satisfaction } & JB1 & My pay is fair for the work I perform \\
\hline & JB2 & Amount of vacation (or Paid Time Off) \\
\hline & JB3 & Sick leave policy \\
\hline & JB4 & Amount of healthcare paid for \\
\hline & JB5 & Dental benefits \\
\hline & JB6 & Vision care benefits \\
\hline & JB7 & Retirement plan benefits \\
\hline & JB8 & Life insurance benefits \\
\hline & JB9 & Disability benefits \\
\hline & JB10 & Tuition reimbursement benefits \\
\hline & JB11 & Amount of vacation (or Paid Time Off) \\
\hline & JB12 & $\begin{array}{l}\text { The leaders of this organization care about their } \\
\text { employees' well being }\end{array}$ \\
\hline & JB13 & Senior leaders live the core values of the organization \\
\hline & JB14 & There is adequate planning of departmental objectives \\
\hline & JB15 & There is adequate follow-through of departmental objectives \\
\hline & JB16 & $\begin{array}{l}\text { The leaders of this organization are open to input } \\
\text { from employees }\end{array}$ \\
\hline & JB17 & $\begin{array}{l}\text { The leaders of this organization care about their } \\
\text { employees' well being }\end{array}$ \\
\hline
\end{tabular}




\section{Continued}

Employee

Turnover

Intentions

ETI1 Most days, I look forward to going to work

ETI2 My job provides me with a sense of meaning and purpose

ETI3 I am proud to work for this organization

ETI4 I feel this organization has created an environment where I can do my best work

ETI5 I am willing to give extra effort to help this organization succeed

ETI6 I plan to continue my career with this organization for at least two more years

ETI7

I would recommend this organization's products/services to a friend

ETI8

I would recommend working here to a friend 